Research Square

\title{
Effect of Processing Parameters On Mechanical Properties of Inconel718 Superalloy Fabricated By Direct Energy Deposit
}

\author{
Tianhao Jia \\ Shandong University \\ Bin Zou ( $\square$ cajetzb@163.com ) \\ Shandong University \\ Wenbo Liu \\ Shandong University \\ Ting Lei \\ Shandong University \\ Hongjian Ding \\ Shandong University
}

\section{Research Article}

Keywords: Inconel718, Direct energy deposit, Laser cladding, Parameters, Mechanical properties

Posted Date: December 17th, 2021

DOI: https://doi.org/10.21203/rs.3.rs-1148378/v1

License: (c) (i) This work is licensed under a Creative Commons Attribution 4.0 International License. Read Full License 


\section{Abstract}

In this study, Inconel718 specimens with good mechanical properties were prepared by direct energy deposit (DED) with different laser processing parameters. The mechanical properties of Inconel718 samples fabricated by laser direct energy deposit method without heat treatment were measured. The fractures and metallographic structures of prepared Inconel718 were observed, and the mechanism of the effect of diverse machining parameters on mechanical properties of Inconel718 was analyzed from the micro level. The results showed the microstructures of depositions of Inconel 718 specimens prepared by DED were compact with fine grains and anisotropic microstructures, where macroscopic defects were barely seen. The mechanical properties and microstructures of Inconel718 were influenced by processing parameters, among which the forming angle and laser power had the most remarkable effect. According to the experimental data, it could be observed that the Inconel718 specimens prepared by DED had the best performance under the circumstance of $1400 \mathrm{~W}$ laser power, $1.0 \mathrm{~mm}$ layer thickness, $600 \mathrm{~mm} / \mathrm{min}$ scanning speed, $1.3 \mathrm{~mm}$ hatch spacing, and $90^{\circ}$ forming angle, whose ultimate tensile strength (UTS) and macro hardness were 1016.10MPa and 36.2HRC respectively. The UTS of Inconel 718 manufactured by DED was close to that of Inconel718 prepared by traditional forging, and even it had higher hardness.

\section{Introduction}

Inconel718 nickel-based superalloy has high strength and hardness, good resistance to wear, thermal corrosion, fatigue and good weldability at high temperature ${ }^{[1]}$. As a result, Inconel718 is widely adopted in the parts used in extremely high temperature such as rocket combustion chambers, turbocharger rotors, nuclear reactors, aerospace and so on ${ }^{[2-4]}$. However, mainly due to the large amount of waste generated during the period of machining and finishing operations, this kind of nickel-based superalloy is quite expensive which will increase the cost of manufacturing, and Inconel718 is typically a category of difficult-to-cut materials, which will easily lead to shorter tool endurance ${ }^{[5]}$. Direct energy deposit (DED), also called laser cladding, is one of the most mature and widely-utilized method of additive manufacturing (AM) technologies, of which main principle is to discretize 3D models and deposit them layer by layer to obtain parts with complex structure ${ }^{[6]}$, this method has the advantages of good forming qualities, fast forming speed and high utilization rate of materials ${ }^{[7,8]}$. With the ability of forming complex shapes, it is a method that frequently used to prepare Inconel718 structural parts of high performance ${ }^{[9,10]}$. Direct energy deposit method can be used to repair the damaged parts, Liu et al. ${ }^{[11]}$ studied the impact on the environment of remanufacturing a cast iron cylinder head block through direct energy deposit method using life cycle assessment method. The results showed that, the remanufacturing of cylinder head block with laser DED technology can achieve greater environmental benefits compared with fabricating a new cylinder head block, and the environmental impact over the entire life cycle could be reduced by $63.8 \%$ on average. Selective laser melting (SLM), a derivative for selective laser sintering (SLS), is another common method for Inconel718 additive manufacturing ${ }^{[7]}$. Both methods of SLM and SLS are based on powder bed fusion technology. Compared with DED technology, the parts prepared by SLM usually have good surface roughness and high machining accuracy, while the mechanical properties of these parts are poor ${ }^{[7]}$. The powder utilization rate of SLM process is low, because of requiring a preset powder bed as a support. As a matter of fact, the SLM method is often used for small complex parts, such as planetary gears, bone scaffolds ${ }^{[12]}$.

Research has been done about the effect of process parameters on the forming performance of direct energy deposit method. Brage et al. ${ }^{[13]}$ worked on repairing a $\mathrm{H} 13$ die via direct energy deposit method in order to study on the structure and mechanical properties of $\mathrm{H} 13$ samples deposited above a substrate of $\mathrm{H} 13$ hot work tool steel. The results showed a highly consistent combination between the deposition and the substrate, along with a structure consisting of columnar and isometric grains resulting from the directional solidification process. The deposition had higher hardness and better wear resistance, and the smooth transition in terms of hardness between the regions was identified as well. Onuike et al. ${ }^{[14]}$ studied the effect of two different groove patterns of rectangle and trapezoid on internal crack repair and the effect of scanning strategy on friction performance of the repaired structure. The results showed that with the use of trapezoidal cross-section, the fusion between deposited material and the part along sidewalls is better and pore defect is less. The scanning strategy both affected the friction coefficient and the composite wear of the material, appropriate defect zone preparation and process parameter optimization, especially build orientation, are critical to ensure high quality repair of metal parts fabricated by laser additive manufacturing technologies. Alhuzaim et al. ${ }^{[15]}$ investigated the influence of laser power on microstructure and properties of Inconel718 single-wall material prepared by direct energy deposit. The results illustrated that a higher thermal gradient due to lower heat input tends to form equiaxed grains and more Nb-segregation, whilst a higher heat input develops columnar grains with low Nb-segregation. The segregations within the interdendritic boundaries increased in size when the heat input 
was increased, whilst the contribution from precipitation strengthening was not significantly evident in the as-fabricated condition. Xu et al. ${ }^{[16]}$ proposed a gradient laser power (GLP) deposit method, which effectively adjusted the morphology and content of the Laves phase, thus improving the mechanical properties of the material. The results indicated that the GLP method not only alleviated heat accumulation but also increased cooling rates and lateral heat dissipation. For GLP samples, the discrete and fine Laves phases tailored with a uniform distribution were featured by fine columnar dendrites with random growth direction, in sharp contrast to their long-chain interconnected configurations obtained by the conventional constant laser power (CLP) deposition method. Compared with CLP samples, GLP samples show compressive residual stress, high hardness and excellent ductility of elongation $30.09 \%$ with comparable strength. Moradi et al. ${ }^{[17]}$ used analysis of variance (ANOVA) to study the influence of scanning speed, powder feeding rate, scanning path and other technological parameters on the process of direct energy deposit of Inconel718 single-wall parts, and the results showed that low scanning speed and high powder feeding speed would lead to the increase of the height and average width of AM samples. Due to the existence of microstructural phase, the change of microhardness tended to be unstable. Under the condition of low scanning speed and unidirectional scanning pattern, a stable wall body can be obtained. In addition, Moradi et al. ${ }^{[17]}$ optimized the processing parameters of laser DED based on statistical analysis, and determined the optimal scanning speed and powder feeding rate. Zhang et al. ${ }^{[18]}$ studied the effects of different heat treatment conditions on the microstructure and cyclic thermal corrosion behavior of deposited Inconel718 alloy, and the results showed that the thermal corrosion dynamics of deposited Inconel718 alloy followed parabolic regulation. The thermal corrosion behavior of laser deposited Inconel 718 alloy under different heat treatment conditions varies. The thermal corrosion performance of the solution aged samples was better than that of the directed aged ones, and the thermal corrosion performance of the directed aged samples was better than that of the deposited samples. Artaza et al. ${ }^{[19]}$ studied the effects of scanning direction and powder flow blockage on the deposit process of alloy Inconel718 from the aspects of powder efficiency, material deposit rate and cladding layer geometry. The experimental results showed that the it was only the four-flow structure that could generate the distribution of circular powder flow. With the increase of the carrier gas rate, the position of the powder focus might move, and the characteristics of the cladding layer would alter because of the blockage of the powder flow, which was particularly obvious at a high powder flow rate. Liu et al. ${ }^{[20]}$ studied the influence of the hybrid deposit strategy on the microstructure and mechanical properties of Inconel718 laser cladding by adopting a deposit strategy combination of two sets of parameters to process layer by layer. The results indicate the hybrid processing strategies have a distinct influence on the crystal growth behavior, grain orientations and sizes, precipitations and associated tensile strengths. Compared with the single processing strategies, the hybrid deposit strategies showed little effect on the ultimate tensile strength with a slightly increased anisotropy under bidirectional scanning pattern, while distinctly improve the ultimate tensile strength with a reduced anisotropy under unidirectional scanning pattern. Jelvani et al. ${ }^{[21]}$ studied the influence of laser power, scanning speed and powder feeding rate on the microstructure of laser-cladded Inconel718. The results showed that the microstructure of Inconel718 prepared by laser cladding is mainly composed of columnar and isometric dendritic crystals, and the number of isometric dendritic crystals increases with the increase of laser power, scanning speed and powder feeding rate.

There were numerous current studies on direct energy deposit of Inconel718, but they appeared to demonstrate the following gaps. Firstly, the research on laser direct energy deposit of Inconel 718 superalloy mainly focused on the optimization of one or two processing parameter, there were little research works on multifactor coupling analysis. Secondly, study on mechanism of effect of heat treatment process on the properties of the deposited materials could be browsed, though it was hard to find how the parameters affect the laser deposit process from microscopic view. In this paper, Inconel 718 specimens was deposited above a 45-steel substrate under different processing parameters by adjusting processing parameters such as laser power, scanning speed, scanning distance, layer thickness and forming angle during laser direct energy deposit. Their ultimate tensile strength (UTS), macro hardness and other mechanical properties were measured. In order to seek out the influencing mechanism of processing parameters on mechanical properties of Inconel 718, scanning electron microscope (SEM) and optical microscope (OM) experiment of the specimens are implemented. The mechanical properties of Inconel 718 prepared by laser DED method and Inconel 718 produced by traditional forging were compared. The solidified microstructure as demonstrated using the dendrite arm spacing (DAS) could be correlated with the solidification mechanisms and cooling rates. The aim of this investigation was to gain a Inconel718 deposition with extremely high performance via adjusting process parameters which are laser power, scanning speed, hatch spacing, layer thickness and forming angle.

\section{Experimental Procedure}

\subsection{Materials}


The Inconel718 nickel-based superalloy powder used in this study was sold in the market, which was prepared by aerosol method. Its elemental composition was shown in Table 1. The powder particle size was in the range of 53-106 $\mu \mathrm{m}$, the particle size distribution was in accordance with the normal distribution, the powder apparent density was $4.23 \mathrm{~g} / \mathrm{cm}^{3}$, the tap density was $5.42 \mathrm{~g} / \mathrm{cm}^{3}$, and the powder Hall flow rate was $16.81 \mathrm{~s} / 50 \mathrm{~g}$. Fig. 1.a showed the SEM image of the powder, and Fig. 1.b selected out a typical Inconel718 powder particle. In order to ensure the standardization of the tests, the material for each test was from same batch and specifications. Before the test, Inconel 718 powder was placed in a drying box and dried at $120^{\circ} \mathrm{C}$ for 120 min to remove water vapor in the powder. The substrate was made of 45-steel with $20 \mathrm{~mm}$ thick. To ensure the forming accuracy of direct energy deposit process, standard heat treatment (solution and aging) was carried out on the substrate in advance. Before the deposit process, the substrate was polished with sandpaper and wiped with alcohol.

Table 1

Element content of Inconel 718 powder

\begin{tabular}{|llllllllllllllll|}
\hline Element & $\mathbf{N i}$ & $\mathbf{C r}$ & $\mathrm{Fe}$ & $\mathrm{Nb}$ & $\mathrm{Mo}$ & $\mathrm{Co}$ & $\mathrm{Ti}$ & $\mathrm{Al}$ & $\mathrm{Si}$ & $\mathrm{Mn}$ & $\mathrm{Cu}$ & $\mathrm{B}$ & $\mathbf{C}$ & $\mathbf{S}$ & $\mathrm{Mg}$ \\
\hline $\mathrm{wt} \%$ & Bal. & 20.62 & 20.60 & 4.81 & 3.04 & 0.024 & 0.71 & 0.28 & 0.003 & 0.05 & 0.093 & - & 0.021 & 0.0035 & - \\
\hline
\end{tabular}

\subsection{Direct energy deposit processing}

The laser direct energy deposit process in this study was based on the laser cladding system of the DMG LaserTec 65 3D Hybrid, a five-axis machining center. Fig. 2.a showed the exterior appearance of the machine tool, and Fig. 2.b showed the laser cladding module of the machine tool. The laser spot diameter was $3 \mathrm{~mm}$, and the $\mathrm{z}$-direction distance from the nozzle to the laser focus was $13 \mathrm{~mm}$. In this paper, we studied the effects of laser power, scanning speed, hatch spacing, layer thickness and forming angle on tensile properties and hardness of Inconel718 specimens fabricated by DED method. The value of the above parameters was shown in Table 2.

Table 2

Selected value of processing parameters

\begin{tabular}{|ll|}
\hline Processing parameters & Value \\
\hline Laser power $P[\mathrm{~W}]$ & $800,1000,1200,1400,1600$ \\
\hline Layer thickness $\delta[\mathrm{mm}]$ & $0.9,1.0,1.1,1.2$ \\
\hline Scanning speed $V[\mathrm{~mm} / \mathrm{min}]$ & $400,600,800,1000$ \\
\hline Hatch spacing $h[\mathrm{~mm}]$ & $1.1,1.3,1.5,1.7$ \\
\hline Forming angle $a\left[^{\circ}\right]$ & $0,90,45$ \\
\hline
\end{tabular}

In this deposit test, the scanning strategy as shown in Fig. 3 was adopted. The scanning strategy of the two adjacent deposit layers is different, and the deposit direction is along the $Z$ axis of the machine tool. In this study, we set up 15 experimental variables. According to the parameters in Table 2, 15 blocks of Inconel718 specimens of $30 \mathrm{~mm} \star 40 \mathrm{~mm} \star 120 \mathrm{~mm}$ were arranged for deposit, that was, one block for one set of parameters. In order to explore the influence of different forming directions on mechanical properties of Inconel718, three different forming angles were set. The schematic diagram of forming angles is shown in Fig. 4.

Each specimen block could be made into 5 standard tensile specimens and 4 hardness specimens by wire cut electrical discharge machining (WCEDM). The thickness of these standard tensile specimens is $3.5 \mathrm{~mm}$, and their dimensions were shown in Fig. 5 . After WCEDM, the surfaces of the standard tensile specimens were polished with metallographic sandpapers to fully remove the surface machining marks and ensure that the surfaces of the tensile specimens were free from defects. For ordinary forged Inconel718 material, the above tensile specimens were directly machined by WCEDM, and the same polishing treatment was implemented.

\subsection{Tensile experiment and hardness measurement}

The tensile test was carried out at room temperature on WDW-50EIII tensile testing machine. The maximum tensile force of the testing machine was $50 \mathrm{KN}$, the gauge length of specimen was $20 \mathrm{~mm}$, he loading rate was $2 \mathrm{~mm} / \mathrm{min}$. Tensile tests were conducted 5 times for each set of parameters, and the ultimate tensile strength (UTS), reduction of area and elongation after fracture of each specimen were measured respectively. The average values of the 5 test results were recorded as the tensile strength, reduction of area and elongation of this set of parameters. Fig. 6 showed the comparison between a standard tensile specimen and a fractured one in this 
test. The fracture morphology of tensile specimens was observed by Carl Zeiss Supra ${ }^{\mathrm{TM}} 55$ thermal field emission scanning electron microscope.

In order to measure the hardness in scanning direction and deposit direction, $\mathrm{X}$ direction and $\mathrm{Z}$ direction of hardness measurement were defined as the same as the machine tool coordinate system, and 4 hardness samples were prepared for each set of parameters. The hardness test was carried out on 200HRS-150 digital Rockwell hardness tester with diamond indenter. The load was $1470 \mathrm{~N}$ and the dwell time was 15 seconds. Each hardness specimen would be measured 10 times in the $X$ direction and 10 times in the $Z$ direction respectively. The $X$ direction and $Z$ direction hardness of the 4 samples were counted and averaged to be the $X$-direction hardness and Z-direction hardness of this set of parameters.

\subsection{Metallographic observation}

In order to observe the microstructure of Inconel718 specimens fabricated by DED method, the specimens were perfectly polished. After erosion in aqua regia for 10 seconds, metallographic images were observed by AxioCamMR5 optical microscope of Carl Zeiss. Volume laser energy density $E$ is the primary factor affecting grain size of direct energy deposit of Inconel718. Volume laser energy density $\mathrm{E}$ is related to laser power, scanning speed, hatch spacing, layer thickness, as shown in Equation 1:

$$
E=\frac{Q}{t}=\frac{P}{V h \delta}(1)
$$

Where $Q$ is the heat input, $P$ is the laser power, $V$ is the scanning speed, $h$ is the hatch spacing, and $\delta$ is the layer thickness ${ }^{[13]}$.

\section{Results And Discussions}

\subsection{Effect of laser power on mechanical properties of Inconel 718 specimens by DED}

In order to explore the effect of laser power on mechanical properties of Inconel718 deposit specimens, it is necessary to keep the scanning speed, hatch spacing, layer thickness and forming angle uniform. The tensile data showed a trend of ultimate tensile strength of the Inconel718 which was increasing first and then decreasing with the increase of power, and the UTS reached top under $1400 \mathrm{~W}$ laser power condition. The hardness of the material increased first and then decreased with the increase of laser power, and the hardness got the highest value under $1400 \mathrm{~W}$ laser power condition as well. Fig. 7 showed the stress-strain curves of Inconel718 specimens fabricated by DED method under the conditions of laser power of $1400 \mathrm{~W}$ and $1600 \mathrm{~W}$ respectively. It could be seen from the figure that the trend of the two curves was the same as that of the Inconel718 sample prepared by the traditional method. The UTS and conditional yield strength (CYS) of Inconel718 under the condition of $1400 \mathrm{~W}$ laser power was $\sigma=953.11 \mathrm{MPa}$ and $\sigma_{0.2}=637.8$ MPa respectively. The UTS and CYS under the condition of $1600 \mathrm{~W}$ laser power was $\sigma=825.28 \mathrm{MPa}$ and $\sigma_{0.2}=602.8 \mathrm{MPa}$ respectively.

The SEM images of the fracture were shown in Fig. 8. The existence of pores could be obviously observed in the fracture. The fracture features were in orderliness and the fracture form was intergranular fracture. Fig. 9 showed the metallographic structure of small isometric branched grains and columnar branched grains with uniform distribution under this condition, which was same as the research results of Jelvana et al ${ }^{[21]}$. Fig. 10 and Fig. 11 showed the SEM images of fracture and OM images of microstructure of Inconel718 samples under the condition of $1600 \mathrm{~W}$ laser power, respectively. By observing fracture images, it could be seen that when the power increased to $1600 \mathrm{~W}$, there were more pore defects in the microstructure. This was because with the increase of laser power, the molten pool became larger and deeper, which was not conducive to the escape of air at the bottom. Fracture forms included a certain number of transgranular fracture, indicating that the grain size was larger at $1600 \mathrm{~W}$. According to the Hall-Petch relationship, the effect of fine-grain strengthening was weakened and therefore caused a reduction of strength ${ }^{[21]}$.

Figure 12 illustrated the relationship between the ultimate tensile strength and hardness measured by the test and the laser power, and Fig. 13 showed the relationship between the elongation and reduction of area measured by the tensile test and the laser power. Laser energy density is the main factor affecting grain size ${ }^{[13,22]}$. With the increase of laser power, the laser energy density saw a linear increase, and the cooling rate of the material in the solidification process decreased ${ }^{[23]}$. The grain had enough time to grow up and therefore its strength decreased. When the laser power was $1600 \mathrm{~W}$, the hardness decreased obviously, because the increase of the laser power reduced the cooling rate of the material in the solidification process, the quenching effect was weakened, so the hardness 
of the workpiece saw a decrease. When the laser power was lower than $1400 \mathrm{~W}$, the width and depth of the molten pool were small, leading to the Inconel718 powder couldn't be fully melted. The Inconel718 sample had low internal density and high porosity under a low laser power condition, and the tensile properties and hardness of the material became poor. With the increase of laser power, the toughness of the material decreased, which was related to the strength of the grain.

\subsection{Effect of scanning speed on mechanical properties of Inconel 718 specimens by DED}

In order to explore the effect of scanning speed on mechanical properties of Inconel718 deposit specimens, it is necessary to keep the laser power, hatch spacing, layer thickness and forming angle uniform. To ensure the powder feeding stability at any scanning speed, the powder feeding speed needed to be matched according to the scanning speed, otherwise the amount of powder would fail to meet the requirement of deposit process. A larger scanning speed needed to be matched with a larger powder feeding speed. Fig. 14 illustrated the relationship between the ultimate tensile strength and hardness measured by the test and the scanning speed, and Fig. 15 showed the relationship between the elongation and reduction of area measured by the tensile test and the scanning speed. As the scanning speed increased, the overall toughness of the material saw an upward trend, mainly due to the improvement of grain strength. As shown in Fig. 16, it could be found that the fracture form under the condition of $1000 \mathrm{~mm} / \mathrm{min}$ scanning speed was uniform intergranular fracture. By observing the curves in Fig. 14, it could be seen that the scanning speed had little effect on the UTS and hardness of the material. The UTS and hardness of the material increased first and then decreased with the increase of the scanning speed, and the mechanical properties gained optimal values when the scanning speed was $600 \mathrm{~mm} / \mathrm{min}$.

This was because with the increase of scanning speed, the laser energy density decreased, the cooling rate of the material in the solidification process increased, which limited the grains to grow, the grain size became smaller, and therefore the strength and hardness increased. At the same time, with the scanning speed increasing, the solidification time decreased, so the gas in the molten pool failed to escape in time, which increased the porosity and caused a reduction of the strength and hardness, as it could be seen easily in Fig. 17. The two influences compensated each other so that the mechanical properties change was not significant. When the scanning speed was equal to $400 \mathrm{~mm} / \mathrm{min}$, the grain size was coarse, resulting in poor tensile strength and hardness. When the scanning speed was faster than $600 \mathrm{~mm} / \mathrm{min}$, the effect of porosity increase on tensile strength and hardness of the material was significantly increased, which made the tensile strength and hardness decrease with the increase of scanning speed.

\subsection{Effect of hatch spacing on mechanical properties of Inconel 718 specimens by DED}

In order to explore the effect of hatch spacing on mechanical properties of Inconel718 deposit specimens, it is necessary to keep the laser power, scanning speed, layer thickness and forming angle uniform. Fig. 18 illustrated the relationship between the ultimate tensile strength and hardness measured by the test and the hatch spacing, and Fig. 19 showed the relationship between the elongation and reduction of area measured by the tensile test and the hatch spacing. Fig. 20 and Fig. 21 respectively showed the SEM images of fracture and metallographic $\mathrm{OM}$ images of the Inconel718 specimens with a hatch spacing of $1.7 \mathrm{~mm}$. It was not difficult to see from the above figures that when the hatch spacing rose to $1.7 \mathrm{~mm}$, the grain of the material had small size and ordered densely, while the porosity on the surface of the specimen increased slightly compared with that of the sample with a hatch spacing of $1.3 \mathrm{~mm}$. By observing the curves in Fig. 18, it could be seen that the hatch spacing had no significant effect on the UTS and hardness of the material, and the UTS of the material generally increased with the increase of the hatch spacing.

This was because with the increase of the hatch spacing, the laser energy density decreased, the cooling rate of the material in the solidification process increased, which limited the grains to grow, the grain size became smaller, and therefore the strength and hardness increased. At the same time, with the increase of hatch spacing, the overlap rate decreased ${ }^{[24]}$, the re-melt of the material decreased, and the quenching effect weakened. Moreover, the chance of gas escape in the molten pool reduced, the probability of porosity rose, which therefore caused reduction of the strength and hardness. These two influences had compensated effect so that the mechanical properties change was not significant. The effect of grain on strength was more critical than that of porosity, in another word, although the increase of scanning spacing would lead to the increase of porosity, the increase remained small, so the tensile strength of materials increased with the increase of hatch spacing from a overall view.

\subsection{Effect of layer thickness on mechanical properties of Inconel 718 specimens by DED}

Page 6/15 
In order to explore the effect of layer thickness on mechanical properties of Inconel718 deposit specimens, it is necessary to keep the laser power, scanning speed, hatch spacing and forming angle uniform. To ensure the powder feeding stability at any layer thickness, the powder feeding speed needed to be matched according to the layer thickness, otherwise the amount of powder wouldn't meet the requirement of deposit process. A larger layer thickness needed to be matched with a larger powder feeding speed. Fig. 22 illustrated the relationship between the ultimate tensile strength and hardness measured by the test and the layer thickness, and Fig. 23 showed the relationship between the elongation and reduction of area measured by the tensile test and the layer thickness. It could be seen from the curves that the UTS and hardness of the material increased firstly and then decreased with the increase of the layer thickness, and the UTS saw the maximum when the layer thickness was $1.1 \mathrm{~mm}$, and the hardness got to peak when the layer thickness was $1 \mathrm{~mm}$. Generally speaking, the effect of the layer thickness on the strength and hardness was not significant.

As the layer thickness increased, the laser energy density decreased, causing the grain size increased so that the grain strength decreased, and therefore the strength and hardness of the material decreased. A certain amount of transgranular fracture could be found in the fracture morphology in Fig. 24, which could confirm the previous theory. As could be seen from metallographic micrograph in Fig. 25, the porosity of the sample reduced when the layer thickness adjusted to be higher. This was because when the layer thickness increased, there would be more powder in the molten pool, and the volume of air in the molten pool decreased. During solidification, it was not easy to retain the unescaped air to transform into pores, which would reduce the porosity and therefore increase the mechanical properties of the material. With the increase of layer thickness, the proportion of re-deposit reduced and the quenching effect weakened. Hence, the effect of layer thickness on strength and hardness was not significant. When the layer thickness was less than $1.1 \mathrm{~mm}$, the reduction of porosity contributed more than the decrease of grain strength to tensile strength, and the UTS increased with the growth of layer thickness. When the thickness was larger than $1.1 \mathrm{~mm}$, the porosity reduction threshold was limited, and the grain strength continued to weaken, making the tensile strength and hardness decrease with the increase of layer thickness. The effect mechanism of porosity and grain strength on material hardness was the same as section 3.3.

\subsection{Effect of forming angle on mechanical properties of Inconel 718 specimens by DED}

In order to explore the effect of forming angle on mechanical properties of Inconel718 deposit specimens, it is necessary to keep the laser power, scanning speed, hatch spacing and layer thickness uniform. Fig. 26 illustrated the relationship between the ultimate tensile strength and hardness measured by the test and the forming angle, and Fig. 27 showed the relationship between the elongation and reduction of area measured by the tensile test and the forming angle.

When the forming Angle was $90^{\circ}$, in another word, when the deposit direction is consistent with the tensile direction of the specimen, the strength and hardness were significantly improved, and the UTS and hardness of the material reached the maximum value of all specimens in this paper. The fracture was characterized by uniform intergranular fracture, with few pores in the cross-section. The material saw densification and barely obvious defect, and evenly distributed isometric grains and columnar grains. These phenomena could be observed in Fig. 28 and Fig. 29, respectively. When the forming angle was $0^{\circ}$, the deposit time for each layer was quite short, the former deposit layer was not adequately cooled down before the next layer deposit started, the heat accumulated more, the quenching effect of the material was significantly enhanced, and the repeated re-deposit made the air in the molten pool fully escape, the porosity of the material was significantly reduced, and the mechanical properties of the material were hence increased.

When sedimentary direction of $45^{\circ}$, with one on each of the cladding layer and cladding layer were all in a certain extend of dislocation, there was less re-deposit during DED process, less heat accumulation, hence, quenching effect was quite weak. Also, the molten pool had lots of air that failed to escape out, the porosity of deposition gained higher. Due to the dislocation between the layers, the interlayer binding force was poor. All these reasons led to this bottom value of UTS, hardness was also under a quite low level. Hence, manufacturers should avoid this forming angle in the practical production process.

\section{Conclusions}

In this study, the effects of laser power, scanning speed, hatch spacing, layer thickness and forming angle on the mechanical properties of Inconel718 superalloy prepared by laser direct energy deposit were investigated by controlling variables. The effect of the above five parameters on the mechanical properties of Inconel718 superalloy prepared by DED was analyzed from the aspects of porosity and microstructure. The following conclusions were achieved. 
1) The forming direction and laser power have the greatest influence on the laser direct energy deposit process of Inconel718. The two parameters have great influence on the grain size, grain distribution and defect formation. Scanning speed, hatch spacing and layer thickness have little effect on mechanical properties, so the selection of machining parameters can be considered from the aspects of improving machining efficiency and reducing machining cost.

2) When the laser power is $1400 \mathrm{~W}$, the scanning speed is $600 \mathrm{~mm} / \mathrm{min}$, the scanning spacing is $1.3 \mathrm{~mm}$, the layer thickness is $1 \mathrm{~mm}$, and the forming angle is $90^{\circ}$, the tensile strength and hardness of Inconel718 samples are the maximum in all data. Under this condition, Inconel718 samples have the lowest porosity with high internal density. The grains are isometric and columnar with uniform and dense distribution, and the fracture morphology is intergranular fracture. Enough heat accumulation is the main reason for the high mechanical properties under this condition.

3) The maximum ultimate tensile strength and hardness of Inconel718 samples obtained by DED method are 1016.1MPa and 36.2HRC, respectively. Compared with the Inconel718 sample obtained by traditional forging, the hardness of the sample obtained by DED is higher while the tensile strength is similar. DED can be used to replace the traditional forging process in the production of small batch of complex parts. Both porosity and grain strength affect the strength of materials. When the porosity is larger than a certain value, the increase of grain strength cannot compensate for the mechanical properties of Inconel718 material weakened by porosity.

\section{Declarations}

Availability of data and material All data generated or analyzed during this study are included in this published article.

Author contribution Tianhao Jia (first author): conceptualization, methodology, validation, formal analysis, investigation, and writing the original draft. Bin Zou (corresponding author): conceptualization, formal analysis, resources, and writing: review and editing. Wenbo Liu and Ting: formal analysis. The author's contribution corresponds to their order. All authors read and approved the final manuscript.

Funding This project was supported by the National Natural Science Foundation of China (No. 51875319) and Shandong Natural Science Foundation of China囚ZR2020ZD05).

Ethics approval No conflict of interest exists in the submission of this manuscript, and the manuscript is approved by all authors for publication. This study does not involve human participants and/or animal studies. I would like to declare on behalf of my co-authors that the work described was original research that has not been published previously and not under consideration for publication elsewhere, in whole or in part. All the authors listed have approved the manuscript that is enclosed.

Consent to participate Not applicable

Consent for publication Not applicable. All data in this paper can be published and verified by all authors.

Conflict of interest The authors declare no competing interests.

\section{References}

1. Pratheesh Kumar S, Elangovan S, Mohanraj R, Ramakrishna JR (2021) A review on properties of Inconel 625 and Inconel 718 fabricated using direct energy deposition. Materials Today: Proceedings,46:7892-7906. doi: 10.1016/j.matpr.2021.02.566

2. Tabernero I, Lamikiz A, Martínez S, Ukar E, Figueras J (2011) Evaluation of the mechanical properties of Inconel 718 components built by laser cladding. Int J Mach Tools Manuf 51:465-470. doi: 10.1016/j.jijmachtools.2011.02.003

3. Wang Y, Zou B, Yin G (2019) Wear mechanisms of Ti(C7N3)-based cermet micro-drill and machining quality during ultra-high speed micro-drilling multi-layered PCB consisting of copper foil and glass fiber reinforced plastics. Ceram Int 45:24578-24593. doi: 10.1016/j.ceramint.2019.08.187

4. Wang Y, Zou B, Wang J, Wu Y, Huang C (2020) Effect of the progressive tool wear on surface topography and chip formation in micro-milling of Ti-6Al-4V using Ti(C7N3)-based cermet micro-mill. Tribol Int 141:105900. doi: 10.1016/j.triboint.2019.105900

5. Lambarri J, Leunda J, García Navas V, Soriano C, Sanz C (2013) Microstructural and tensile characterization of Inconel 718 laser coatings for aeronautic components. Opt Lasers Eng 51:813-821. doi: 10.1016/j.optlaseng.2013.01.011 
6. Hu Y, Zou B, Xing H, Liu J, Chen Q, Wang X, Li L (2021) Preparation of Mn-Zn ferrite ceramic using stereolithography 3D printing technology. Ceramics International.. doi: 10.1016/j.ceramint.2021.11.248

7. Gong G, Ye J, Chi Y, Zhao Z, Wang Z, Xia G, Du X et al (2021) Research status of laser additive manufacturing for metal: a review. Journal of Materials Research and Technology 15:855-884. doi: 10.1016/j.jmrt.2021.08.050

8. Liu X, Zou B, Xing H, Huang C (2020) The preparation of ZrO2-Al2O3 composite ceramic by SLA-3D printing and sintering processing. Ceram Int 46:937-944. doi: 10.1016/j.ceramint.2019.09.054

9. Aydogan B, O'Neil A, Sahasrabudhe H (2021) Microstructural and mechanical characterization of stainless steel 420 and Inconel 718 multi-material structures fabricated using laser directed energy deposition. J Manuf Process 68:1224-1235. doi: 10.1016/j.jmapro.2021.06.031

10. Xing H, Zou B, Liu X, Wang X, Chen Q, Fu X, Li Y (2020) Effect of particle size distribution on the preparation of ZTA ceramic paste applying for stereolithography 3D printing. Powder Technol 359:314-322. doi: 10.1016/j.powtec.2019.09.066

11. Liu Z, Jiang Q, Li T, Dong S, Yan S, Zhang H, Xu B (2016) Environmental benefits of remanufacturing: A case study of cylinder heads remanufactured through laser cladding. J Clean Prod 133:1027-1033. doi: 10.1016/j.jclepro.2016.06.049

12. Li Y, Ding Y, Munir K, Lin J, Brandt M, Atrens A, Xiao Y et al (2019) Novel $\beta$-Ti35Zr28Nb alloy scaffolds manufactured using selective laser melting for bone implant applications. Acta Biomater 87:273-284. doi: 10.1016/j.actbio.2019.01.051

13. Braga V, Siqueira RHM, Atilio I, Mansur R, Vieira D, Chen DL, Lima MSF (2021) Microstructural and mechanical aspects of laser metal deposited H13 powder for die repair. Materials Today Communications 29:102945. doi: 10.1016/j.mtcomm.2021.102945

14. Onuike B, Bandyopadhyay A (2019) Additive manufacturing in repair: Influence of processing parameters on properties of Inconel 718. Mater Lett 252:256-259. doi: 10.1016/j.matlet.2019.05.114

15. Alhuzaim A, Imbrogno S, Attallah MM (2021) Controlling microstructural and mechanical properties of direct laser deposited Inconel 718 via laser power. J Alloys Compd 872:159588. doi: 10.1016/j.jallcom.2021.159588

16. Xu L, Chai Z, Chen H, Zhang X, Xie J, Chen X (2021) Tailoring Laves phase and mechanical properties of directed energy deposited Inconel 718 thin-wall via a gradient laser power method. Materials Science and Engineering: A 824:141822. doi: 10.1016/j.msea.2021.141822

17. Moradi M, Hasani A, Pourmand Z, Lawrence J (2021) Direct laser metal deposition additive manufacturing of Inconel 718 superalloy: Statistical modelling and optimization by design of experiments. Opt Laser Technol 144:107380. doi: 10.1016/j.optlastec.2021.107380

18. Zhang J, Zhang Q, Zhuang Y, Kovalenko V, Yao J (2021) Microstructures and cyclic hot corrosion behavior of laser deposited Inconel 718 alloy under different heat treatment conditions. Opt Laser Technol 135:106659. doi: 10.1016/j.optlastec.2020.106659

19. Artaza T, Ramiro P, Ortiz M, Alberdi A, Lamikiz A (2019) Effects of the Nozzle Tip Clogging and the Scanning Direction on the Deposition Process During Laser Metal Deposition of Alloy 718 Using a Four-Stream Discrete Nozzle. Procedia Manufacturing 41:264-271. doi: 10.1016/j.promfg.2019.07.055

20. Liu Z, Zhu Q, Zhang X (2021) Tailoring microstructure and mechanical property of laser powder deposited Inconel 718 superalloy via hybrid processing strategies. J Manuf Process 68:1837-1848. doi: 10.1016/j.jmapro.2021.07.005

21. Jelvani S, Shoja Razavi R, Barekat M, Dehnavi MR, Erfanmanesh M (2019) Evaluation of solidification and microstructure in laser cladding Inconel 718 superalloy. Opt Laser Technol 120:105761. doi: 10.1016/j.optlastec.2019.105761

22. Yeoh YC, Macchi G, Jain E, Gaskey B, Raman S, Tay G, Verdi D et al (2021) Multiscale microstructural heterogeneity and mechanical property scatter in Inconel 718 produced by directed energy deposition. J Alloys Compd 887:161426. doi: 10.1016/j.jallcom.2021.161426

23. Simchi A (2006) Direct laser sintering of metal powders: Mechanism, kinetics and microstructural features. Materials Science and Engineering: A 428:148-158. doi: 10.1016/j.msea.2006.04.117

24. Cao J, Liu F, Lin X, Huang C, Chen J, Huang W (2013) Effect of overlap rate on recrystallization behaviors of Laser Solid Formed Inconel 718 superalloy. Opt Laser Technol 45:228-235. doi: 10.1016/j.optlastec.2012.06.043

\section{Figures}




\section{Figure 1}

SEM images of Inconel718 powder used for DED process. (a) 500 times magnified. (b)2000 times magnified.



\section{Figure 2}

DMG MORI LaserTEC 65 3D Hybrid machining center. (a) exterior; (b) laser head.

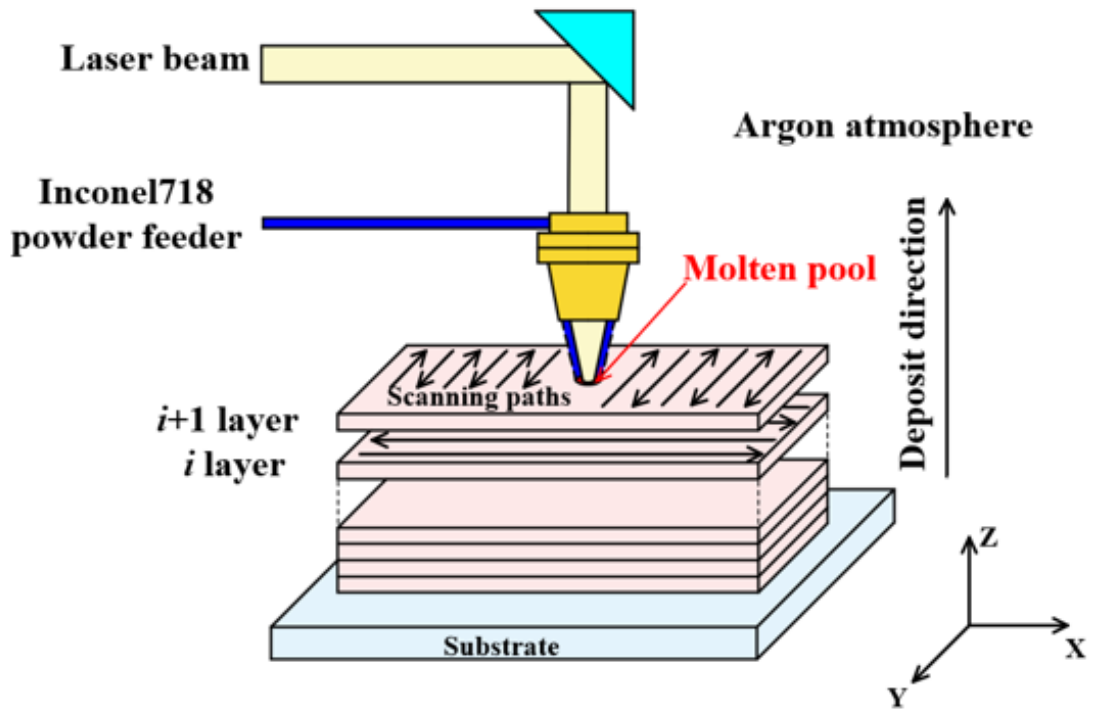

\section{Figure 3}

Schematic diagram of Inconel718 deposit process and scanning strategy in this experiment 


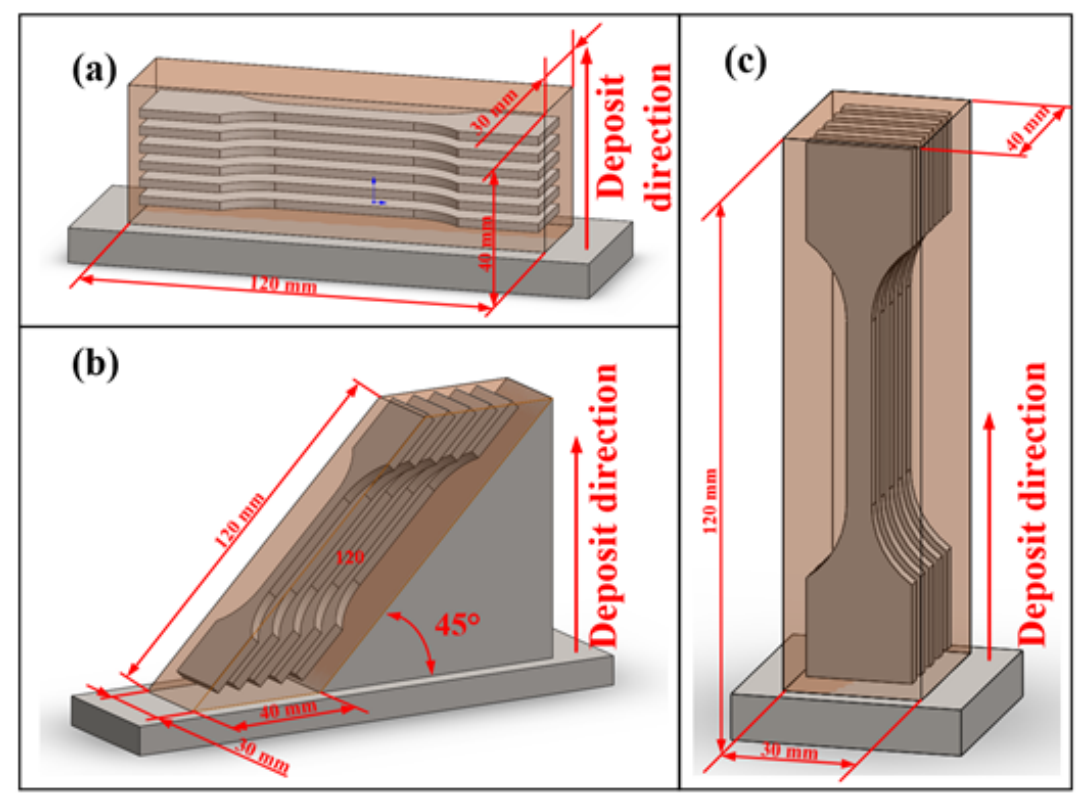

Figure 4

Schematic diagram of forming angle. (a) $0^{\circ}$; (b) $45^{\circ}$; (c) $90^{\circ}$.

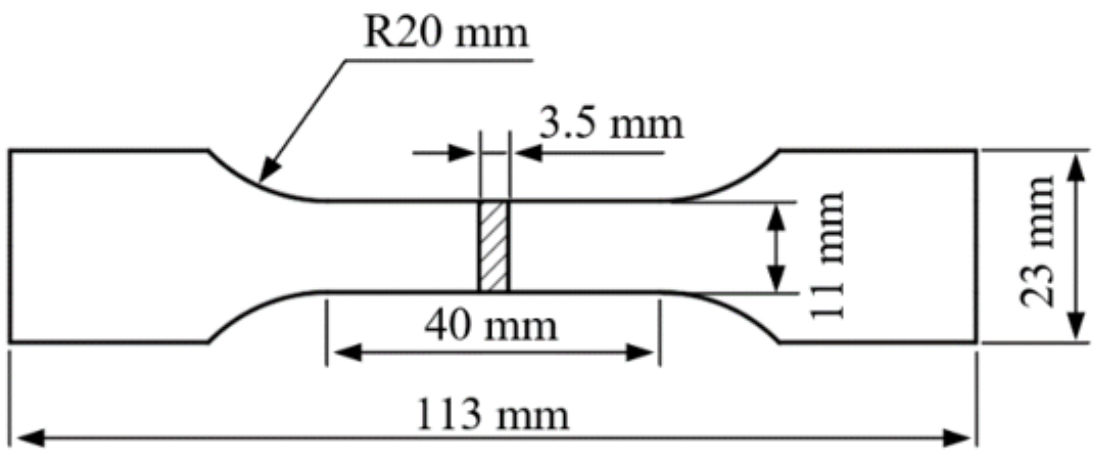

Figure 5

Dimensions of standard tensile specimens. 


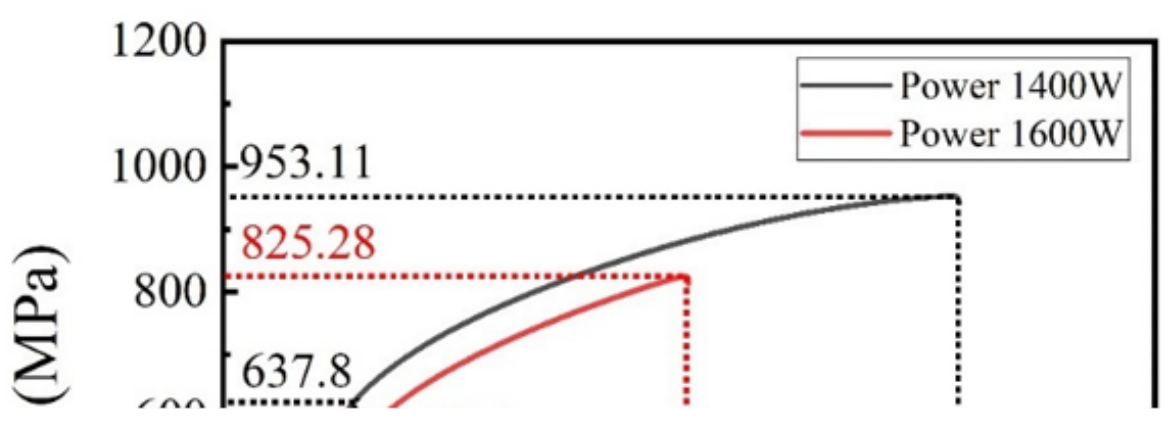

\section{Figure 7}

The stress-strain curves of Inconel718 specimens fabricated by DED method under the conditions of laser power of $1400 \mathrm{~W}$ and $1600 \mathrm{~W}$ respectively.

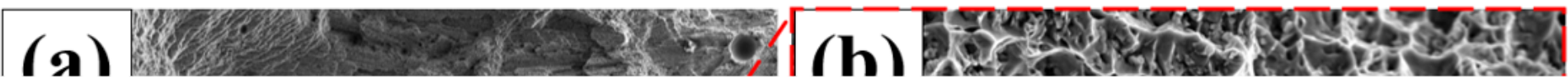

\section{Figure 8}

SEM images of fracture under the condition of $1400 \mathrm{~W}$ laser power, $600 \mathrm{~mm} / \mathrm{min}$ scanning speed, hatch spacing $1.3 \mathrm{~mm} \square$ layer thickness $1 \mathrm{~mm}$ and $0^{\circ}$ forming angle. (a) 200 times magnified $\mathbb{( b )} 5000$ times magnified.

\section{Figure 9}

OM images of metallographic microstructure under the condition of $1400 \mathrm{~W}$ laser power, $600 \mathrm{~mm} / \mathrm{min}$ scanning speed, hatch spacing $1.3 \mathrm{~mm}$ layer thickness $1 \mathrm{~mm}$ and $0^{\circ}$ forming angle. (a) 100 times magnified $\mathbb{( b )} 500$ times magnified. 


\section{Figure 10}

SEM images of fracture under the condition of $1600 \mathrm{~W}$ laser power. (a) 200 times magnified; (b) 5000 times magnified.

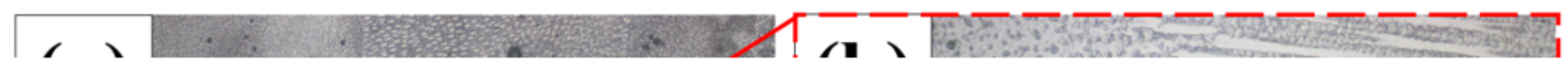

\section{Figure 11}

OM images of metallographic microstructure under the condition of $1600 \mathrm{~W}$ laser power. (a) 100 times magnified; (b) 500 times magnified.

\section{Figure 12}

The relationship between UTS, hardness and laser power obtained by tests.

\section{Figure 13}

The relationship between reduction of area, elongation and laser power obtained by tests.

\section{Figure 14}

The relationship between UTS, hardness and scanning speed obtained by tests

\section{Figure 15}

The relationship between reduction of area, elongation and scanning speed obtained by tests.

\section{Figure 16}

SEM images of fracture under the condition of $1000 \mathrm{~mm} / \mathrm{min}$ scanning speed. (a) 200 times magnified; (b) 5000 times magnified. 


\section{Figure 17}

OM images of metallographic microstructure under the condition of $1000 \mathrm{~mm} / \mathrm{min}$ scanning speed. (a) 100 times magnified; (b) 500 times magnified.

\section{Figure 18}

The relationship between UTS, hardness and hatch spacing obtained by tests.

\section{Figure 19}

The relationship between reduction of area, elongation and hatch spacing obtained by tests.

\section{Figure 20}

SEM images of fracture under the condition of $1.7 \mathrm{~mm}$ hatch spacing. (a) 200 times magnified; (b) 5000 times magnified.

\section{Figure 21}

OM images of metallographic microstructure under the condition of $1.7 \mathrm{~mm}$ hatch spacing. (a) 100 times magnified; (b) 500 times magnified.

\section{Figure 22}

The relationship between UTS, hardness and layer thickness obtained by tests.

\section{Figure 23}

The relationship between reduction of area, elongation and layer thickness obtained by tests.

\section{Figure 24}


SEM images of fracture under the condition of $0.9 \mathrm{~mm}$ layer thickness. (a) 200 times magnified; (b) 5000 times magnified.

\section{Figure 25}

OM images of metallographic microstructure under the condition of $0.9 \mathrm{~mm}$ layer thickness. (a) 100 times magnified; (b) 500 times magnified.

\section{Figure 26}

The relationship between UTS, hardness and forming angle obtained by tests.

\section{Figure 27}

The relationship between reduction of area, elongation and forming angle obtained by tests.

\section{Figure 28}

SEM images of fracture under the condition of $90^{\circ}$ forming angle. (a) 200 times magnified; (b) 5000 times magnified.

\section{Figure 29}

OM images of metallographic microstructure under the condition of $90^{\circ}$ forming angle. (a) 100 times magnified; (b) 500 times magnified. 